Preparation or provocation? Student Perceptions of Active Shooter Drills

\author{
Michael G. Huskey* \\ Nadine M. Connell \\ The University of Texas at Dallas
}

* Corresponding author 


\begin{abstract}
Several highly publicized incidents of school violence in the past two decades have highlighted the importance of school safety and crisis preparation for students, parents, and school administrators. While prior research has focused on the effectiveness of various security and crisis preparation measures, few studies have analyzed student perceptions of these policies. The current study utilizes survey data collected from students at a public university in the southwestern United States to evaluate whether active shooter drills experienced in high school were related to negative student outcomes. Results show that experiencing an active shooter drill in high school was associated with significant increases in student fear, inflated perceptions of risk, and a decrease in perceptions of school safety. Implications for future research and policy initiatives regarding active shooter drills are discussed, specifically, the need for increased transparency, standardization of drills, and addressing effective methods of implementing active shooter drills in schools.
\end{abstract}

Keywords: School shooting, lockdown drills, perceptions, school safety, fear 


\section{Preparation or provocation? Student perceptions of active shooter drills}

Fear of crime and perceptions of school safety remain salient issues for criminologists, parents, and school administrators (Hughes, Gaines \& Pryor, 2015). Fueled by several highly publicized school shootings in the United States over the past two decades, these incidents have increased scrutiny and prompted questions of student safety, campus preparedness, and proper security protocols (Kaminski, Koons-Witt, Thompson, \& Weiss, 2010; Kupchick \& Bracy, 2009). Despite extensive media coverage, school shooting incidents such as the events at Marjory Stoneman Douglas High School in Florida are statistically rare. Some studies have estimated that the risk of death from a school shooting is less than one in one million annually (Regoli \& Hewitt, 2000); for context, the risk of dying in a motor vehicle accident is 1 in 114 (National Safety Council, 2016). Recent data from the Center for Disease Control's (CDC) School-Associated Violent Death Surveillance System continues to support the idea that schools are safe places, noting that the victimization rate for single-victim school-associated youth homicide was 0.03 per 100,000 students from July 1994 to June 2016 and 0.008 per 100,000 students for multiple-victim school-associated homicide between July 1994 and June 2017 (Holland et al, 2019).

However, in an effort to reduce the fear of crime and increase perceptions of school safety among students and parents, many schools across the United States have implemented emergency procedures in preparation for a potential school shooting event (i.e. an active shooter on school grounds) (Council of State Governments, 2014). Generally speaking, however, the efficacy of such approaches is unknown and the wide variety of options available make navigating the landscape difficult for schools, law enforcement, and researchers. Additionally, prior literature has suggested that some of the measures that schools have implemented can have 
negative effects on students, such as increasing levels of fear (Schreck \& Miller, 2003). The current study evaluates whether another common security initiative, active shooter drills, have an effect on levels of student fear, perceived risk, or perceptions of school safety.

In a joint publication between the National Association of School Psychologists and the National Association of School Resource Officers (2014), Best Practice Considerations for Schools in Creating Active Shooter and Other Armed Assailant Drills, three basic models of active shooter drills are described: lockdown drills (i.e. active-shooter drills, armed assailant drills, etc.); active-shooter simulations; and, options-based approaches that incorporate aspects from a "run, hide, fight" model. Lockdown drills focus on relocating students as far away from harm as possible (Trump, 2000). This procedure traditionally involves "locking the door, moving students out of sight, and requiring students to remain quiet within the room" (The National Association of School Psychologists \& The National Association of School Resource Officers, 2014). Active shooter simulations incorporate the use of technology (e.g. announcements made via an intercommunications system or other electronic communication), props (e.g. simulated gunfire via airsoft guns or other simulated weapons, fake blood, etc.) and actors (e.g. local police officers, student or staff volunteers) to simulate an active shooter event. Active shooter simulations are intended to facilitate positive decision making among students and staff in extreme pressure situations (Poland, 2016; The National Association of School Psychologists \& The National Association of School Resource Officers, 2014). Finally, options-based drills based on the Run, Hide, Fight model attempt to improve traditional lockdown drills by encouraging staff to make informed decisions based on the evolving nature of an active shooter event. These types of responses have been adopted by schools, government agencies, and major corporations. 
The Run, Hide, Fight model is federally endorsed by the Department of Homeland Security and instructs individuals to "run if you can," "hide if you must," and "fight if you have to" (Briggs \& Kennedy, 2016). The Run, Hide, Fight model was originally developed as a response to workplace violence but has since been adapted to address active shooter situations in schools (The National Association of School Psychologists \& The National Association of School Resource Officers, 2014). One example of an options-based program is the Alert Lockdown Inform Counter and Evacuate (ALICE) training program. Developed by former lawenforcement officer Greg Crane in 2014, ALICE is currently utilized by schools, churches, businesses, and government agencies (ALICE Training Institute, 2014). Another variation on the run, hide, fight model has been developed by the Advanced Law Enforcement Rapid Response Training (ALERRT) Center at Texas State University. Extending their renowned law enforcement training, ALERRT created a civilian response to active shooter events (CRASE) titled "Avoid, Deny, Defend." With the assistance of $\$ 72$ million in state and federal funding, the program has been taught to more than 200,000 civilians (Advanced Law Enforcement Rapid Response Training (ALERRT) Center at Texas State University, 2018).

According to the Indicators for School Crime and Safety report from 2018, active shooter drills (particularly lockdown drills) have become institutionalized in many schools across the country, with $95 \%$ of schools in the 2015-2016 school year reporting that they had drilled students on lockdown procedures (Musu, Zhang, Wang, Zhang, \& Oudekerk, 2019). Despite their prevalence, little is known about the effectiveness of these drills in terms of keeping students safe (Peterson, Sackrison \& Polland, 2015; Regan, 2013). Several factors, including the homogeneity of drill procedures implemented, ethical considerations of experiments, and lack of universal criteria make evaluating active shooter drills difficult. For example, Poland (2016) 
notes that the most important goal of an effective active shooter/crisis drill is to teach students to listen and follow the instructions of the nearest adult but suggests that active shooter simulations (similar to those described above) do a poor job of achieving this goal. In contrast, the report issued by the National Association of School Psychologists and The National Association of School Resource Officers (2014) argues that the most important goal of an active shooter drill is to save lives by empowering and preparing students and staff to respond quickly and responsibly in the event of an active shooter. Of course, this is an untestable premise, as there is no way to know whether an active school shooter drill does such a thing; simulation studies cannot always anticipate all real-world threats and there is no moral or ethical way to test these procedures in the real world. Indeed, the experiences of going through these drills could have long-term negative consequences on the psychological well-being of students, who then enter school in a state of fear instead of safety (see Schrek \& Miller 2003 for examples of how security procedures can increase student fear). So, while the authors note that active shooter simulations can provide an opportunity for students, school officials, and law enforcement to rehearse skills and protocols involved in an active shooter response, they do not acknowledge unintended consequences of such experiences. Despite the proliferation of such programs, little empirical research exists to lend clarity, not only on whether such tactics save lives, but also on whether the cost to students' well-being is worth the potential outcome.

Historically, research on fear of crime in the school environment has looked at the effects of physical and nonphysical (Schreck \& Miller, 2003) security measures, such as metal detectors, security guards, security cameras, visitor sign-in requirements, locked doors, etc. on fear of crime (Tillyer, et al, 2011) and negative perceptions of school safety (Connell, 2018). While results have been mixed, Schreck and Miller (2003) note that highly visible security measures, 
such as metal detectors, corresponded with higher levels of student fear. It is possible that rehearsing crisis drills, such as an active shooter drill, has a negative effect on fear and perceptions of school safety by reinforcing the idea that an active shooter situation could occur (Fremont, 2004; Schreck \& Miller, 2003; Skiba et al, 2000; Zhe \& Nickerson, 2007). However, it is also possible that active shooter drills decrease fear in students and improve perceptions of school safety due to a sense of preparedness (Poland, 2016). Connell (2018) notes that research evidence suggesting differential effects in response to security procedures could be explained by a cohort effect, wherein students in more recent cohorts have grown used to, and comfortable with, visible security measures as they become more normalized in school and public settings (e.g. the airport).

Efforts to reduce student fear of crime and negative perceptions of school safety remain important because of their correlation with adverse student behaviors, including skipping classes, avoiding school altogether, and decreased concentration when present (Barrett, Jennings, \& Lynch, 2012; Randa \& Wilcox, 2012). While research on the efficacy of active shooter drills is noticeably scarce, prior research has examined the effect of these drills on other outcomes, such as levels of student preparedness, perceptions of school safety, and levels of student anxiety (Zhe \& Nickerson, 2007). In the context of increased media scrutiny of high-profile school shooting incidents, the current study seeks to expand the literature on active shooter drills by evaluating whether they are related to negative outcomes such as an increase in student fear, an increase in the perceived risk of victimization, and decreased perceptions of school safety.

\section{Student Perceptions of Fear and Risk}

One important distinction established in previous literature on fear of crime is that fear and perceptions of risk are conceptually different concepts (Ferraro, 1995; Rountree \& Land, 
1996). Ferraro (1995) notes that risk perception is a cognitive evaluation of one's chances of victimization, whereas fear is an emotional response. While some research on fear of crime has distinguished risk perception and fear of crime as related, yet distinct concepts (Rountree \& Land, 1996; Tillyer, Fisher, \& Wilcox., 2011), others have failed to incorporate both concepts into their empirical models on school shootings (Stretesky \& Hogan, 2001). Because of the conceptual distinction between fear and risk perception, researchers have suggested that measures for both levels of fear and perceptions of safety (i.e., perceived risk) should be utilized in order to provide a more complete picture (Elsass, Schildkraut, \& Stafford, 2016). Furthermore, Hughes, Gaines, and Pryor (2015) note that perceptions of safety and levels of student fear are highly correlated and that they are often analyzed with similar explanatory models (Hughes, Gaines, \& Pryor, 2015). The current study seeks to evaluate the effect of active shooter drills on both outcomes by constructing separate models for levels of student fear, perceived risk, and perceptions of school safety.

Historically, research on fear of criminal victimization has focused on adult samples (Clemente \& Kleiman, 1976; Ferraro, 1995). Within the past two decades, however, several researchers have turned their attention to examining fear of crime among children and adolescents, particularly within the school environment (Connell, 2018; Hughes, Gaines \& Pryor, 2015; May \& Dunway, 2000; Mowen \& Freng, 2018; Schreck \& Miller, 2003; Tillyer, Fisher \& Cox, 2011). Established literature has identified several personal and environmental correlates to feelings of fear among students, including association with delinquent peers, weapon carrying, media exposure, social integration, levels of school disorder, and demographic characteristics such as age, race, and grade (Hughes et al, 2015). Additionally, prior experiences with victimization both in and outside of the school environment have also been tied to fear in 
students (Alvarez \& Bachman, 1997; May \& Dunway, 2000; Parker \& Ray, 1990; Skogan, 1987; Schreck \& Miller, 2003; Tillyer et al, 2011).

Research has shown that increased fear of victimization at school can contribute to a variety of negative outcomes, such as lack of concentration (Boulton, Trueman, \& Murray, 2008), avoiding certain places within the school building, or avoiding school altogether (Barrett, Jennings, \& Lynch, 2012; Randa \& Wilcox, 2012). Balfanz and Byrnes (2012) note that school avoidance as a consequence of fear can contribute to lower test scores, increased chances of failing classes, reduced graduation odds, and lower college attendance. Patton, Wooley, and Hong (2012) also determined that there are negative relationships between fear at school, time spent studying, and self-esteem.

While objectively schools are the safest places for children and adolescents to spend their time (DeVoe, et al, 2005), decreasing fear of crime within the school environment remains a top priority for parents, administrators, and the federal government (Schreck \& Miller, 2003). With the assistance of federal and state funding, several physical and non-physical security measures have been implemented across the country (Schreck \& Miller, 2003). Nonphysical security measures consist of things such as visitor sign-in policies, locker checks, and hall passes. Physical security measures include metal detectors, security guards, security cameras, and locked doors (Perumean-Chaney \& Sutton, 2013). In addition to these physical and nonphysical security measures, many schools have implemented security exercises, such as active shooter drills, in response to several highly publicized school shooting incidents. As of 2014, the Council of State Governments Justice Center (2014) reported that 33 states had statutes in place that specifically required schools and school districts to have a "comprehensive school safety or emergency plan" that included protocols for an active shooter on school grounds (p. 2). Evidence on the 
effectiveness of physical security measures in lowering student victimization is not conclusive (Burrow \& Apel, 2008; Shreck \& Miller, 2003). Some research has even suggested that security measures that are coercive or highly visible to students, such as metal detectors or security cameras, can increase student fear and negative perceptions of school safety (Bachman, Randolph, \& Brown, 2011; Kupchick, Brent, \& Mowen, 2015; Tillyer et al, 2011). Recent research, however, suggests that this could be changing as security measures become more commonplace in both schools and in public (Connell, 2018).

\section{School Security Measures and Drills}

Research on student perceptions of school safety as a result of experiencing active shooter drills is also scarce. As pointed out above, much of the prior literature has centered on the effects of various school security measures and policies, such as metal detectors, security cameras, locked doors, and visitor log-in requirements, on student perceptions of safety (Connell, 2018; Perumean-Cheny \& Sutton, 2013). Using data collected by the National Longitudinal Study of Adolescent Health (AddHealth) in the mid-1990s, Perumean-Chaney and Sutton (2013) found that highly visible security measures such as metal detectors and security cameras decreased student perceptions of safety at school. The researchers further noted that perceptions of safety at school were also affected by factors such as race, class size, prior victimization experience, and neighborhood conditions (Perumean-Chaney \& Sutton, 2013). Bachman, Randolph, and Brown (2011) discovered similar findings in their analysis of the 2005 School Crime Supplement for the National Crime Victimization Survey. Although their study focused on student fear as the outcome variable, many similar security measures were found to have deleterious effects on student perceptions of fear at school, including security guards and metal detectors. Similar to Perumean-Chaney and Sutton (2013), the student's race was also identified 
as an important factor when it comes to the relationship between highly visible security measures and fear. For example, security guards were found to only significantly affect fear in white students (Bachman, Randolph, \& Brown, 2011). Although these studies reached similar conclusions about the negative effects of security measures on levels of student fear and their perceptions of school safety, it is possible that the data used in these studies is now outdated. A more recent study has suggested that increased awareness of school safety measures can have a positive effect on the likelihood of a student feeling safe at school (Connell, 2018). Results from data collected on 3,073 high school students in a mid-Atlantic state revealed that students with increased awareness of school security measures had higher odds of feeling safer at school (Connell, 2018). The findings suggest a cohort effect may exist when it comes to the explaining relationship between school security measures and a students' perception of school safety. Specifically, Connell (2018) notes that highly publicized events such as the terrorist attacks on September 11, 2001 or the Columbine shootings, have radically affected the security landscape and potentially the way people (e.g. students) view various security measures and procedures. Students that lack memories of such events may perceive security measures, including those at school, differently than previous generations. Because mass school shootings appear to be on the rise (Holland et al, 2019) and active shooter drills in schools have become increasingly more common (Council of State Governments, 2014; Musu et al, 2019) it is similarly possible that students in the current study view active shooter drills differently than previous generations who may remember a time without them.

Despite research on the effects of security measures on student perceptions of safety outlined above, there is a distinct absence of research on active shooter drills and their effects on student fear and perceptions of school safety. Therefore, it is difficult to determine whether a 
cohort effect exists between different student populations as it applies to the effects of active shooter drills. Outside of the current study, Zhe and Nickerson (2007) represent one of the only studies to directly evaluate the effects of these types of drills on students. Utilizing a sample of seventy-four $4^{\text {th }}-6^{\text {th }}$ graders in upstate New York, the researchers sought to examine the impact of an active shooter training session and an intruder drill on students' knowledge acquisition, anxiety levels, and their perceptions of school safety versus a control group. Students were randomly assigned to either the treatment condition or a placebo control group. The intruder crisis drill utilized in the experimental group was a variation on a traditional "lockdown" drill that required students to relocate away from doors and windows, remain quiet throughout the drill, and follow instructions provided by their teacher.

Results indicated that students could successfully complete parts of the drill (relocating to safe parts of the room) but they were unable to succeed in other areas (remaining quiet throughout the drill). Additionally, the researchers reported that there were no differences in levels of state anxiety (i.e. a psychophysiological reaction to anxiety that is usually temporary) or perceptions of school safety between the control and experimental groups (Leal, Goes, da Silva, Teixeira-Silva, 2017; Zhe \& Nickerson, 2007). It is possible that the effects of the active shooter training session were moderated by the age of the participants, similar to moderating effects of race, gender, and age among other school security measures (Bachman, Randolph, \& Brown, 2011; Connell, 2018; Perumean-Chaney \& Sutton, 2013).

In light of the findings by Zhe and Nickerson (2007), the current study seeks to expand our knowledge on the relationship between active shooter drills and student fear and perceptions of safety. By surveying students directly on their experience with active shooter drills, we paint a more contextualized picture on the effects of various school security procedures on their 
perceptions of school safety and school climate. Survey data were collected from undergraduate students $(\mathrm{N}=379)$ at a large Southwestern university in order to explore their experiences and perceptions of active shooter drills in high school (i.e. 9th through 12th grade). The study investigates the effect that participating in an active shooter drill in high school had on levels of student fear, perceived risk, and perceptions of school safety.

\section{Method}

\section{Participants and Procedure}

Data for this study were collected via a convenience sample of undergraduate students from a large Southwestern university during the Spring 2018 semester. Students were surveyed in order to assess their experiences and perceptions of active shooter drills in high school. Seven Criminology and Criminal Justice instructors that were listed as the instructor of record for ten traditional learning (i.e. in-person) courses in the Spring of 2018 were contacted via email to request permission to visit their classes and conduct the survey. An additional four faculty members from other disciplines, such as Environmental Science, Public Affairs/Administration, and Innovation and Entrepreneurship were also contacted via referral. In total, nine out of the eleven faculty members that were contacted agreed to allow their classes to be surveyed and responses were collected from 379 students $(\mathrm{N}=379)$ across 12 different courses.

The final sample was comprised of $15 \%$ freshman, $15 \%$ sophomores, $44 \%$ juniors, and $26 \%$ seniors. These percentages are closely aligned with the overall university population of undergraduate students which was $12 \%$ freshman, $15 \%$ sophomores, $33 \%$ juniors, and $39 \%$ seniors. In general, the demographics of the sample were also similar to that of the wider university population in terms of age and race. Specifically, the majority of students in the wider university population (66\%) and the sample (57\%) were both non-white and the average age of 
both groups was 22 years old. However, in terms of gender males appeared to be underrepresented in the sample (49\%) compared to the wider student population $(58 \%)$.

Additionally, while the original sample included students who attended high school in the United States and those that attended high school internationally, the percentage of students who reported attending high school outside of the United States was quite low (3\%). This is in line with the wider university population in which international students only represented $4 \%$ of the total undergraduate population. Students that reported that they did not attend high school in the United States $(\mathrm{N}=12)$ were excluded from the final sample because their experience was deemed to not be relevant to the current study which is focused on a United States context.

Student responses were collected using a self-report survey, with students completing the survey during the first 15 minutes of one of their regularly scheduled class periods. Students were briefed on the details of the study via a written script that was read to the class prior to administration of the survey. The students were informed that no identifying information was being collected, their participation was completely voluntary, and that they could stop participation at any point. No incentives were offered for participation. All survey protocols, including the survey instrument, were approved by the Institutional Review Board at the sponsoring university. All undergraduate students enrolled in the selected courses, and in attendance on the day of the survey, were invited to participate.

Three separate models were used to examine relationships between participation in active shooter drills and subsequent outcomes. Two ordinary least squares (OLS) regression models were used in order to test the effect of active shooter drills on levels of student fear at school and perceptions of risk. Additionally, an ordered logistic regression model was used to analyze the relationship between active shooter drills and perception of school safety. Several control 
variables were included in each model. Descriptive statistics for the sample can be seen in Table 1.

\section{INSERT TABLE 1 HERE}

\section{Dependent Variables}

According to the prior literature, fear of crime can be broken down into two unique constructs, fear and perceived risk. Fear is generally considered an emotional response to crime or symbols associated with a specific crime, while perceived risk can be thought of as a general cognitive response based on the perceived risk of victimization (Ferraro, 1995; Ferraro \& LaGrange, 1992; Rountree \& Land, 1996). Results from principal components analysis (PCA) confirmed that the dependent variables loaded onto two separate components which we subsequently labeled student fear and perceived risk. These two components were treated as two separate dependent variables, both of which are described below. Results from the PCA, including individual factor scores can be found in Table 2

Student Fear: The first dependent variable was a measure of student fear. Student fear was based on responses for three individual questions: "Did you ever fear being attacked traveling to or from school?;" and "Were you ever fearful of being attacked on the school bus?;" and "I was worried about an active shooter situation in my high school." Student responses were coded as 1 for "yes" and 0 for "no." These responses were combined into an additive scale that measured the emotional component of student fear. The Cronbach's alpha measure for the combined scale was .52. Individual item information for the scale can be found in Table 3 .

Perceived Risk: The second dependent variable was a measure of the student's perceived risk of victimization at school. Two dichotomous variables were combined into a single measure of risk perception. The measures included the following questions: "did you ever stay home from 
school because you thought someone might attack or harm you in the school building?; and "did you ever avoid going to school because you felt threatened on school property?” Student responses were coded as 1 for "yes" and 0 for "no." Combined, the measure of risk perception had a Cronbach's alpha measure of 0.70 suggesting that these two measures have a moderately high level of internal consistency. Individual item information is available in Table 3.

\section{INSERT Table 2 HERE.}

Perceptions of School Safety: The third dependent variable was a measure that represented the student's perception of school safety. Students were asked to rate, on a 10-point scale, how safe they felt at their high school. Connell (2018) notes that students tend to rate their safety at school as relatively high. The data in the current study confirms this trend. The average rating of safety among the students in the sample was 8.30 on a scale of $1-10(\mathrm{SD}=1.62$; range 2-10). This variable was negatively skewed, with fewer than $22 \%$ of respondents reporting feeling less safe than average. In order to conserve the ordered nature of the variable, but also address the skewness of the data, the variable was transformed into a four-level ordinal variable of approximate quartiles. Respondents that answered between 2 and 7 (of 10) on the scale were put in the lowest category $(21.3 \%$ ), those who responded 8 (of 10) were put in the second category $(27.1 \%$ ), those who responded 9 (of 10$)$ were put in the third category $(25.7 \%)$ and those that indicated $10 / 10$ on the scale were put in the highest category (25.9\%).

\section{Independent Variables}

Experience with an Active Shooter Drill: In order to measure whether a student experienced an active shooter drill in high school, students were asked: "did you ever experience an emergency drill for an active shooter while you were in high school?" Responses were coded 
as $0=$ "no" and $1=$ "yes." The majority of the sample reported experiencing at least one active shooter drill while they were in high school (56.4\%).

Security Awareness: Research has shown that several schools across the United States have implemented security measures such as locked entrance and exit doors, security guards or assigned police officers, metal detectors, locker checks, requirements that visitors sign in, security cameras, a student code of conduct, staff or other adults supervising the hallways, or a requirement that students had to wear badges or picture identification (Bachman, Randolph, \& Brown, 2011; Connell, 2018; Musu-Gillette, Zhang, Wang, Kemp, Diliberti \& Oudekerk, 2018; Perumean-Cheny \& Sutton, 2013; Schreck \& Miller, 2003). Furthermore, several studies have noted that security measures can have an effect on a student's level of fear and their perceptions of school safety (Bachman, Randolph, \& Brown, 2011; Connell, 2018; Perumean-Cheny \& Sutton, 2013). Therefore, a measure of security awareness was controlled for in the final models. The survey asked students to identify whether or not their high school employed any of the previously mentioned security protocols. Students responses were recorded as "yes," "no," or “not sure." Similar to Connell (2018), an index was created to measure the number of security protocols that the student was aware of at their high school with values ranging from 0 to 9 . This was done in order to control for the potential confounding effects that other security protocols may have had on levels of student fear and their perceptions of school safety. On average, students indicated that they were aware of between 5 and 6 security protocols $(\bar{x}=5.94, \mathrm{SD}=$ 1.62). Individual item information for the index can be found in Table 3.

School Climate: Previous studies have shown that positive school climate is associated with positive outcomes including lower levels of bullying (Lee \& Song, 2012; Mucherah, Finch, White \& Thomas, 2018) and violence (Steffgen, Recchia, \& Viechtbauer, 2013). In order to 
control for school climate, six questions, adapted from measures of student attachment and bond to school (Newhouse, 2001) were used to create an additive scale measuring school climate. These six questions include dimensions such as a sense of student belonging, student cooperation, and relationships between students and teachers. Students were asked to respond to each of the following statements: "I felt like I belonged in my high-school;" "students really liked my high school;" "groups of students did not get along together in my high school;", "the teachers were more like friends than authority figures in my high school;" and, "the teachers went out of their way to help the students in my high school." The third measure was reverse coded so that each measure equated to a statement that was indicative of a more positive school climate. Responses were coded as $0=$ "mostly false" and $1=$ "mostly true." Scale scores ranged from 0 to 6 with higher scores indicating a more positive school environment $(\bar{x}=4.38, \mathrm{SD}=$ 1.50). Individual item information is in Table 3.

\section{INSERT Table 3 HERE}

School Characteristics: Various indicators were included to examine the effect of school characteristics on each of the dependent variables. Students were asked to indicate whether they attended a public $(90.3 \%)$ or private $(9.7 \%)$ high school. Additionally, students were asked to estimate the size of their high school graduating class in order to get a sense of the size of the high school that student attended. Students were given five choices: "fewer than 100 students," “100 to 600 students," “601 to 800 students," "801 to 1000 students," or “more than 1000 students." Due to the variance in the distribution of this measure, responses were collapsed into three groups: small (i.e. fewer than 100 students) (10.7\%), medium (i.e. 100 to 800 students) (58.2\%), and large (801 to 1000 students) (31.3\%), with medium serving as the reference category in the final models. Lastly, students were asked to indicate which category best 
described their high school's location, "rural (away from suburbs and urban areas)" (5.7\%), suburban (surrounded by neighborhoods and houses)" (80.9\%), or "urban (located in a city-type area)" (13.4\%). Due to the small percentage of rural schools, the "rural" variable was collapsed into the "suburban" variable and a dichotomous measure for "urban" or "not urban" was created, with the latter serving as the reference category in the final models.

Demographic Characteristics: In order to control for individual-level characteristics, several demographic variables were included. Race was recorded as "Hispanic or Latino" (23.7\%), "White" (43.3\%), "Black or African American" (6.5\%), Native American or American Indian" (1.2\%), Asian/Pacific Islander" (23.2\%), or “Other” (2.1\%). In subsequent analyses, responses for race were dummy coded as 1 for "White" and 0 for "Non-White," with Non-White serving as the reference category. Additionally, a bivariate measure for gender was included with 1 representing "male" and 0 representing "female," with male serving as the reference category. Students in the sample were between 18 and 59 years of age, with a median age of 21 years old. An additional variable describing the average number of years it had been since each student completed high school are also presented in Table 1. The majority of the sample (73\%) completed high school 4 years prior to participating in the study $(\bar{x}=4.13, \mathrm{SD}=5.27){ }^{1}$

\section{Results}

Table 4 reports the results from the ordinary least squares regression model used to examine whether experiencing an active shooter drill in high school was significantly predictive of student fear, net of other controls. Results for Model 1 indicated that there was a significant, positive correlation between experiencing an active shooter drill in high school and levels of student fear $(\beta=.19, \mathrm{SE}=.07, p=.01)$. Experiencing an active shooter drill increased student fear by .19 , net of other controls. Students that attended a high school in an urban area were also 
more fearful than those that $\operatorname{did} \operatorname{not}(\beta=.32, \mathrm{SE}=.11, p=.00)$. Attending high school in an urban area increased levels of student fear by .32, net of other controls. Additionally, school climate and security awareness were also significantly correlated with student fear. For every one-unit increase on the school climate scale, levels of student fear decreased by $.05(\beta=-.05$, $\mathrm{SE}=.02, p=.03)$. Similarly, higher security awareness was associated with lower levels of student fear $(\beta=-.05, \mathrm{SE}=.02, p=.04)$. For each additional safety measure that students were aware of, their level of fear decreased by .05 . All of the above variables were significant at the $p$ $<.05$ level of significance, except for attending high school in an urban area which was significant at the $p<.01$ level. Overall, the results indicate that the variables in Model 1 explain roughly $7.53 \%$ of the variance in levels of student fear $\left(\mathrm{R}^{2}=.0753\right)$.

\section{INSERT Table 4 HERE}

Table 5 reports the results from the ordinary least squares regression model used to examine the effects of experiencing an active shooter drill in high school student perceptions of risk, net of other controls. Results for Model 2 indicated that there was a significant, positive correlation between experiencing an active shooter drill in high school and levels of perceived risk $(\beta=.10, \mathrm{SE}=.04, \mathrm{p}=.02)$. Experiencing an active shooter drill increased levels of perceived risk by .10 , net of other controls. Students that attended a high school in an urban area also had higher levels of perceived risk than those that $\operatorname{did} \operatorname{not}(\beta=.16, \mathrm{SE}=.06, \mathrm{p}=.00)$. Attending high school in an urban area increased levels of perceived risk by .16, net of other controls. Additionally, there was a significant, negative correlation between school climate and levels of perceived risk. Students with higher levels of school climate had lower levels of perceived risk. In other words, for every one-unit increase on the school climate scale, levels of perceived risk 
were decreased by $.03(\beta=-.03, \mathrm{SE}=.01, \mathrm{p}=.03)$. Model 2 explained roughly $6.1 \%$ of the variance in levels of student fear $\left(\mathrm{R}^{2}=.0605\right)$.

\section{INSERT Table 5 HERE}

Finally, in order to estimate the effect of experiencing an active shooter drill on perceptions of school safety, an ordered logistic regression model was performed. The results of the ordered logistic regression (Model 3) are displayed in Table 6. The results indicate that the odds of a student reporting higher levels of safety are $53 \%$ lower for students who experienced an active shooter drill $(p<.001)$. Additionally, for each increase in a student's level of school climate, the odds of reporting higher levels of safety are $97 \%$ greater than students with lower school climate scores $(p<.001)$. Neither student gender nor race had a significant effect on their perceptions of school safety. School-level variables such as the number of security measures that the student was aware of in high school, whether they attended a private high school, the location of their high school, and the size of their high school had no significant effects on a student's perception of school safety. Table 5 shows that the model explains $9.1 \%$ of the variance in perceptions of school safety (Pseudo $\left.\mathrm{R}^{2}=.0905\right)$.

\section{INSERT Table 6 HERE}

\section{Discussion}

This research examined the importance of active shooter drills, along with several other school-level factors, in determining levels of student fear, perceptions of risk, and perceptions of school safety. Consistent with previous research, student experiences at school impact their level of fear (Hughes, Gaines \& Pryor, 2015; May \& Dunway, 2000; Schreck \& Miller, 2003; Tillyer, Fisher \& Cox, 2011) and their perceptions of school safety (Bachman, Randolph, \& Brown, 2011; Connell, 2017; Perumean-Chaney \& Sutton, 2013; Zhe \& Nickerson, 2007). The central 
finding to the current study was that students who experienced an active shooter drill in high school reported feeling increased levels of fear, increased perceptions of risk, and a decrease in perceptions of school safety. This finding is in contrast with Zhe and Nickerson (2007), who previously found that active shooter drills (i.e. lockdown drills) have no significant effect on student perceptions of school safety. It is possible that this deviation is due to differences in the age of participants within each study. Zhe and Nickerson $(2007)$ used a sample of $4^{\text {th }}-6^{\text {th }}$ graders while the current study was only concerned with the participants' high school experience. It is possible that cohort effects may explain the discrepancy between the results found in the current study and those reported in Zhe and Nickerson (2007). For example, survey responses for the current study were collected over a decade later when school shooting incidents have become a much more prominent part of media discussion (note that all data was collected prior to the shooting in Parkland, Florida). However, due to a lack of studies that have specifically asked students about their experience with active shooter drills, greater support for generational changes in student perceptions of these drills would ultimately require more research in this area. We hope, however, that this can be a stepping stone to that kind of inquiry, especially as school shooting drills become more commonplace for students at all age levels.

In addition to participation in active shooter drills, greater awareness of school security measures also had significant effects on student fear. Previous research on the relationship between school security measures, fear, and perceptions of school safety has historically been inconsistent. Some researchers, such as Ferraro (1995) and Schreck and Miller (2003; see also Mowen \& Freng, 2018) have argued that the presence of highly conspicuous school security measures increase student perceptions of safety and increase fear. The results in the current study are more consistent with the findings in Tillyer et al (2011) and Connell (2018) which suggest 
that greater student awareness of school security measures can actually decrease fear. However, it is also worth noting that while security awareness was significantly correlated with lower levels of student fear, it had no significant effect on levels of perceived risk or perceptions of school safety. Also, because it was not the main focus of this study, it is unclear which security measures played the largest role in decreasing student fear among the students in the sample. However, previous research has suggested that security measures such as security guards and metal detectors play the largest role in affecting student perceptions of safety (Bachman, Randolph, \& Brown, 2011).

Additionally, the current study also found that higher school climate was significantly correlated with a decrease in student fear and levels of perceived risk, as well as an increase in perceptions of school safety. This is in line with prior literature that has reported a correlation between school climate and a number of outcomes including school disorder (Welsh, 2001), willingness to report a weapon on school property (Connell, Barbieri, \& Reingle Gonzalez, 2015), and perceptions of school safety among students and faculty (Bosworth, Ford, \& Hernandaz, 2011; Connell, 2018).

In terms of individual differences, student gender had no significant effect on any of the three outcome measures. While gender differences in fear of crime have been identified in some prior studies (Connell, 2018; May \& Dunway, 2000; Schreck \& Miller, 2003), the results found here are consistent with Alvarez and Bachman (1997) who noted no gender differences in student fear. In addition to gender, age and race were also not found to be significantly correlated to levels of student fear, perceived risk, or perceptions of school safety. However, there were some significant differences among school characteristics. Specifically, high school location was positively correlated to student fear. Students who attended a high school in an urban area were 
significantly more fearful than those that attended school in rural or suburban areas. However, there were no significant differences in student fear or perceptions of safety between students who attended a private versus a public high school. Additionally, while school size (notably the student to teacher ratio, which was not measured here) is an important physical dimension of school climate (Loukas, 2007), it failed to produce a significant effect on fear of crime or perceptions of school safety among participants.

\section{Limitations}

Despite novel findings on the effects of active shooter drills on levels of student fear and perceptions of school safety, this study is not without its limitations. The reliance on a convenience sample of undergraduate students at a single university limits generalizability. Furthermore, while it is possible that the sample was geographically diverse in terms of the number of states represented, the survey did not ask in which state the student attended high school. Overall, generalizability is limited. The data collected were also subject to the potential pitfalls of survey data, including voluntary response bias. Because participation in the study was not mandatory, it is possible that responses were biased towards students who have strong opinions on/prominent experiences with active shooter drills in schools.

Also, while the current study made every effort to control for relevant extraneous variables, there were some variables that the survey failed to capture that could affect the relationship between experiencing an active shooter drill in high school and levels of student fear and perceptions of school safety. For example, students were not asked about their major. It is possible that a student's major could lead to differential perceptions of active shooter drills based on what they have learned in their classes. This knowledge could subsequently affect their recollections of past experiences with active shooter drills. For example, students that are 
majoring in criminal justice or education, two topics in which school shootings may be a more prominent topic of discussion, may recall their past experiences differently than an economics or music major who likely do not spend as much time discussing the topic of school shootings. Future research should control for the respondent's major and investigate whether it has any effect on their recall of prior experiences with active shooter drills.

Another limitation of the current study is the potential for recall bias that is associated with many retrospective studies, specifically those dealing with attitudes (Turner \& Martin, 1984). The current study is particularly susceptible to this type of bias because it utilized data that was collected from all undergraduate students, instead of just freshman students. Although the majority $(73 \%)$ of our sample were students that had completed high school within the four years prior to completing the survey, it is possible that older students, such as non-traditional college students are more susceptible to problems recalling past events, which may introduce recall bias (Eisenhower, Mathiowetz \& Morganstein, 1991). However, the emotional salience of an event can often enhance recall (Eisenhower, Mathiowetz \& Morganstein, 1991, pp. 137-139). Therefore, it is possible that an emotionally salient event (i.e. an active shooter drill) is more likely to be remembered than a non-salient event. While this emotional salience can increase recall, it can also produce biased results. Research has shown that although memories of emotions (e.g. fear) are fairly accurate, they are subject to systematic bias in the event that an individual uses their current feelings to appraise past experiences (Levine \& Safer, 2002). Therefore, it is possible that students who may have felt an extreme emotional response during or immediately following an active shooter drill in high school answered survey questions differently than those that did not. 
Lastly, the measure for student perceptions of school safety was also not as exhaustive as would be preferred, therefore our general measure was unable to identify the specific situations in which students may have felt unsafe. It is possible that a more comprehensive measure could provide school administrators with valuable data on the best times to perform active shooter drills so as to minimize fear and increase perceptions of school safety. The survey also did not ask students how many active shooter drills they experienced in high school. Future studies should explore whether a dosage effect exists whereby students who experience more active drills have a greater probability of negative reactions such as increased fear, increases in perceived risk, and a decrease in perceptions of school safety.

\section{Policy Implications}

Despite the limitations noted above, the results of the current study provide suggest that policymakers and school administrators should consider the unintended negative consequences that active shooter drills can have on their students. Because active shooter drills can potentially increase fear among students, increase their perceived risk of victimization, and decrease their perceptions of school safety, policymakers and school administrators should focus on implementing drills that maximize student preparedness while minimizing the potential for these negative reactions. Previous literature has suggested that some active shooter drills, namely active shooter simulations, which often involve the use of props and actors, could be more likely to produce negative reactions among students than more traditional lockdown drills, especially if they are carried out without advanced warning to students and staff (Rygg, 2015). Additionally, Poland (2016) argues that active shooter simulations are less effective at achieving the ultimate goal of an active shooter drill which is teaching students to listen and follow the instructions of the nearest adult. Although the current findings do not directly speak to which type of active 
shooter drills are more likely to elicit negative effects, they do provide support for the argument that policymakers should carefully weigh the benefits of preparedness that comes from active shooter drills with their potential for negative consequences. Prior literature suggests that one policy avenue that could minimize negative reactions to these drills is increasing lines of communication between school administrators, staff, students, and parents prior to conducting any type of active shooter drill (Rygg, 2015)

Another related policy suggestion would be for district administrators to come up with standardized procedures for the implementation and execution of active shooter drills and ensure that students and parents are made aware of these procedures. Oftentimes there is a great deal of variation in the types of drills that schools decide to implement, even among different schools in the same district (Rygg, 2015). This lack of consistency and transparency can lead to confusion among students which may ultimately contribute to negative effects such as an irrational fear response or an overestimation of the risk of victimization at school, particularly as it applies to becoming the victim of an active shooter.

Additionally, in order to assuage student fear, school administrators and staff should clearly outline the district's procedures for active shooter drills and be explicit about when drills will occur, how they will be handled, and what they hope to accomplish with each drill. School staff should create an open dialogue with students about the realities of school shooting events. This information could be delivered by local law enforcement, school resource officers, and school administrators via classroom discussions or student assemblies. Honest and open communication about these events would ensure that students are aware that although active shooter drills are an important part of being prepared in the event of a crisis, the chances of being 
victimized in a school shooting event are quite low and that overall, schools are very safe places (Holland et al, 2019; Musu-Gillette et al, 2018).

\section{Conclusion}

This study offers key insight into the effects of active shooter drills on students, specifically their potential to increase fear, inflate perceptions of victimization, and decrease perceptions of school safety. Active shooter drills (e.g. lockdown drills) have become commonplace in many American schools (Council of State Governments, 2014; Musu, Zhang, Wang, Zhang, \& Oudekerk, 2019). Despite their pervasiveness, very little is known about the effectiveness of these drills in keeping students safe or the way these drills affect students (Peterson, Sackrison \& Polland, 2015; Regan, 2013). Very few prior studies have asked students directly about their experiences with these types of drills, and those that have were carried out among younger student samples (Zhe \& Nickerson, 2007). In light of increased scrutiny surrounding responses to school shootings, the current study adds to the understanding of student safety, campus preparedness, and proper security protocols from a student perspective. The findings presented here suggest that active shooter drills significantly increase student fear and decrease their perceptions of school safety. However, additional research is needed to determine if differences in types of drills (e.g. lockdown drills versus active shooter simulations), their execution (i.e. when and where), and their frequency, differentially affect students on these outcomes. Determining the answers to these questions could provide school administrators with valuable information to assist in the design and implementation of active shooter drills. While schools will no doubt remain some of the safest places for children (Musu-Gillette et al, 2018), it is important that procedures implemented to protect students are done so in such a way that the potential for negative outcomes is minimized. 
Note

1. This variable was created based on the assumption that most students complete high school at the age of 18 . While we recognize that some students may have completed high school before or after the age of 18 , other studies using nationally representative data on high school seniors have reported a modal age of 18 years (McCabe, Boyd, Cranford, \& Teter, 2009). Further support for this assumption is illustrated by the fact that $86 \%$ of the Freshman in our sample were 18 years of age. 


\section{References}

Advanced Law Enforcement Rapid Response Training (ALERRT) Center at Texas State University. (2018). About the advanced law enforcement rapid response training (ALERRT) program. Retrieved from https://alerrt.org/page/about

ALICE Training Institute. (2014). Active shooter response. Retrieved from https://www.alicetraining.com/our-program/alice-training/

Alvarez, A., \& Bachman, R. (1997). Predicting the fear of assault at school and while going to and from school in an adolescent population. Violence and Victims, 12(1), 69. doi:

\section{$10.1177 / 0044118 X 10366674$}

Bachman, R., Randolph, A., \& Brown, B. L. (2011). Predicting perceptions of fear at school and going to and from school for African American and white students: The effects of school security measures. Youth \& Society, 43(2), 705-726. doi:10.1177/0044118X10366674

Balfanz, R., \& Byrnes, V. (2012). The importance of being in school: A report on absenteeism in the nation's public schools. The Education Digest, 78(2), 4-9.

Barrett, K. L., Jennings, W. G., \& Lynch, M. J. (2012). The relation between youth fear and avoidance of crime in school and academic experiences. Journal of School Violence, 11(1), 1-20. doi:10.1080/15388220.2011.630309

Bosworth, K., Ford, L., \& Hernandaz, D. (2011). School climate factors contributing to student and faculty perceptions of safety in select Arizona schools. Journal of School Health, 81(4), 194-201. doi:10.1111/j.1746-1561.2010.00579.x

Boulton, M. J., Trueman, M., \& Murray, L. (2008). Associations between peer victimization, fear of future victimization and disrupted concentration on class work among junior school pupils. British Journal of Educational Psychology, 7878(3), 473-489. 
Briggs, T. W., \& Kennedy, W. G. (2016). Active shooter: An agent-based model of unarmed resistance. In Proceedings of the 2016 Winter Simulation Conference (WSC), 3521-3531. https://doi.org/10.1109/WSC.2016.7822381

Burrow, J. D., \& Apel, R. (2008). Youth behavior, school structure, and student risk of victimization. Justice Quarterly, 25(2), 349-380. doi:10.1080/07418820802025181

Clemente, F., \& Kleiman, M. B. (1976). Fear of crime among the aged. The Gerontologist, 16(3), 207- 210. Retrieved from https://academic.oup.com/gerontologist

Connell, N. M. (2018). Fear of crime at school. Youth Violence and Juvenile Justice, 16(2), 124136. doi:10.1177/1541204016680407

Connell, N. M., Barbieri, N., \& Reingle Gonzalez, J. M. (2015). Understanding school effects on students' willingness to report peer weapon carrying. Youth Violence and Juvenile Justice, 13(3), 258-269. doi:10.1177/1541204014544512

Council of State Governments Justice Center. (2014). School safety plans: A snapshot of legislative action (1st ed.). New York: Council of State Governments Justice Center. Retrieved from https://csgjusticecenter.org/wp-content/uploads/2014/03/NCSL-SchoolSafety-Plans-Brief.pdf

DeVoe, J. F., Peter, K., Kaufman, P., Miller, A., Noonan, M., Snyder, T. D., \& Baum, K. (2005). Indicators of school crime and safety: 2005. Education Statistics Quarterly, 6(4), 1-182. Eisenhower, D., Mathiowetz, N. A., \& Morganstein, D. (2004). Recall error: Sources and bias reduction techniques. Measurement errors in surveys, 125-144. In Biemer, P. P., Groves, R. M., L. E., Mathiowetz, N. A. \& Sudman, S. (eds), Measurement errors in surveys (pp. 127-144). New York, NY. Wiley. 
Elsass, H. J., Schildkraut, J., \& Stafford, M. C. (2016). Studying school shootings: Challenges and considerations for research. American Journal of Criminal Justice, 41(3), 444-464.

Ferraro, K. F. (1995). Fear of crime: Interpreting victimization risk. Albany, NY: Albany, NY : State University of New York Press.

Ferraro, K. F., \& LaGrange, R. L. (1992). Are older people most afraid of crime? Reconsidering age differences in fear of victimization. Journal of gerontology, 47(5), S233-S244.

Fremont, W. P. (2004). Childhood reactions to terrorism-induced trauma: A review of the past 10 years. Journal of the American Academy of Child \& Adolescent Psychiatry, 43(4), 381392. doi:10.1097/00004583-200404000-00004

Holland, K. M., Hall, J. E., Wang, J., Gaylor, E. M., Johnson, L. L., Shelby, D., ... \& SchoolAssociated Violent Deaths Study Group. (2019). Characteristics of school-associated youth homicides-United States, 1994-2018. Morbidity and Mortality Weekly Report, 68(3), 53 .

Hughes, M. R., Gaines, J. S., \& Pryor, D. W. (2015). Staying away from school. Youth Violence and Juvenile Justice, 13(3), 270-290. doi:10.1177/1541204014538067

Kaminski, R. J., Koons-Witt, B. A., Thompson, N. S., \& Weiss, D. (2010). The impacts of the Virginia Tech and Northern Illinois University shootings on fear of crime on campus. Journal of Criminal Justice, 38(1), 88-98. doi:10.1016/j.jcrimjus.2009.11.011

Kupchik, A., \& Bracy, N. L. (2009). The news media on school crime and violence. Youth Violence and Juvenile Justice, 7(2), 136-155. doi:10.1177/1541204008328800

Kupchik, A., Brent, J. J., \& Mowen, T. J. (2015). The aftermath of Newtown: More of the same. British Journal of Criminology, 55(6), 1115-1130. 
Leal, P. C., Goes, T. C., da Silva, L. C. F., \& Teixeira-Silva, F. (2017). Trait vs. state anxiety in different threatening situations. Trends in psychiatry and psychotherapy, 39(3), 147-157

Lee, C., \& Song, J. (2012). Functions of parental involvement and effects of school climate on bullying behaviors among South Korean middle school students. Journal of Interpersonal Violence, 27(12), 2437-2464. https://doi.org/10.1177/0886260511433508

Levine, L. J., \& Safer, M. A. (2002). Sources of bias in memory for emotions. Current Directions in Psychological Science, 11(5), 169-173. https://doi.org/10.1111/1467$\underline{8721.00193}$

Loukas, A. (2007). What is school climate? National Association of Elementary School Principals, 5(1), 1-3. Retrieved from https://www.naesp.org/sites/default/files/resources/2/Leadership_Compass/2007/LC2007 v5n1a4.pdf.

May, D. C., \& Dunway, G. (2000). Predictors of fear of criminal victimization at school among adolescents. Sociological Spectrum, 20(2), 149-169. doi:10.1080/027321700279938

McCabe, S., Boyd, C., Cranford, J., \& Teter, C. (2009). Motives for nonmedical use of prescription opioids among high school seniors in the United State: self-treatment and beyond. (Clinical report). Archives of Pediatrics \& Adolescent Medicine, 163(8), 739744. https://doi.org/10.1001/archpediatrics.2009.120

Mowen, T.J. \& Freng, A. (2018). Is more necessarily better: School security and perceptions of safety among students and parents in the United States. American Journal of Criminal Justice. doi: https://doi.org/10.1007/s12103-018-9461-7 
Mucherah, W., Finch, H., White, T., \& Thomas, K. (2018). The relationship of school climate, teacher defending and friends on students' perceptions of bullying in high school. Journal of adolescence, 6262, 128-139.

Musu, L., Zhang, A., Wang, K., Zhang, J., and Oudekerk, B.A. (2019). Indicators of school crime and safety: 2018 (NCES 2019-047/NCJ 252571). National Center for Education Statistics, U.S. Department of Education, and Bureau of Justice Statistics, Office of Justice Programs, U.S. Department of Justice. Washington, DC.

Musu-Gillette, L., Zhang, A., Wang, K., Zhang, J., Kemp, J., Diliberti, M., and Oudekerk, B.A. (2018). Indicators of school crime and safety: 2017 (NCES 2018-036/NCJ 251413). National Center for Education Statistics, U.S. Department of Education, and Bureau of Justice Statistics, Office of Justice Programs, U.S. Department of Justice. Washington, DC.

National Association of School Psychologists \& National Association of School Resource Officers. (2014). Best practice considerations for schools in active shooter and other armed assailant drills [Brief]. Bethesda, MD: National Association of School Psychologists. Retrieved from: https://www.nasponline.org/resources-andpublications/resources/school-safety-and-crisis/best-practice-considerations-for-schoolsin-active-shooter-and-other-armed-assailant-drills

National Safety Council. (2018). Injury facts chart. Retrieved from: https://www.nsc.org/worksafety/tools-resources/injury-facts/chart

Newhouse, C. (2001). Development and use of an instrument for computer-supported learning environments. Learning Environments Research, 4(2), 115-138. doi:1012411332666 
Parker, K. D., \& Ray, M. C. (1990). Fear of crime: An assessment of related factors. Sociological Spectrum, 10, 29-40.

Patton, D. U., Woolley, M. E., \& Hong, J. S. (2012). Exposure to violence, student fear, and low academic achievement: African American males in the critical transition to high school. Children and Youth Services Review, 34(2), 388-395.

doi:10.1016/j.childyouth.2011.11.009

Perumean-Chaney, S., \& Sutton, L. (2013). Students and perceived school safety: The impact of school security measures. American Journal of Criminal Justice, 38(4), 570-588. doi:10.1007/s12103-012-9182-2

Peterson, J., Sackrison, E., \& Polland, A. (2015). Training students to respond to shootings on campus: Is it worth it? Journal of Threat Assessment and Management, 2(2), 127-138. doi: $10.1037 / \operatorname{tam} 0000042$

Poland, S. (2016). Keep schools safe: Planning plays a key role in preventing school violence. American School Board Journal, 203 (4), 24-25. Retrieved from https://psychology.nova.edu/news-events/SchoolBoardJournalKeepingSchoolsSafe.pdf

Randa, R., \& Wilcox, P. (2012). Avoidance at school. Youth Violence and Juvenile Justice, 10(2), 190-204. doi:10.1177/1541204011423765

Regan, M. F. (2013). A false sense of security. The School Administrator, 70(9), 26-29. Retrieved from https://www.aasa.org/content.aspx?id=29880

Regoli, R. M., \& Hewitt, J. D. (2000). Delinquency in society. New York: McGraw-Hill. 
Rountree Wilcox, P., \& Land, K. C. (1996). Perceived risk versus fear of crime: Empirical evidence of conceptually distinct reactions in survey data. Social forces, 74(4), 13531376.

Rygg, L. (2015). School shooting simulations: At what point does preparation become more harmful than helpful. Children's Legal Rights Journal. J., 35, 215.

Schreck, C. J., \& Miller, J. M. (2003). Sources of fear of crime at school. Journal of School Violence, 2(4), 57-79. doi:10.1300/J202v02n04_04

Skiba, R., Boone, K., Angela, F., Wu, T., Strussell, A., \& Peterson, R. (2000). Preventing school violence: A practical guide to comprehensive planning. The Safe and Responsive Schools Project, Indiana Policy Center, Indiana University, (1), 2-36.

Skogan, W. (1987). The impact of victimization on fear. Crime \& Delinquency, 33(1), 135-154

Steffgen, G., Recchia, S., \& Viechtbauer, W. (2012). The link between school climate and violence in school: A meta-analytic review. Aggression and Violent Behavior. https://doi.org/10.1016/j.avb.2012.12.001

Stretesky, P. B., \& Hogan, M. J. (2001). Columbine and student perceptions of safety: A quasiexperimental study. Journal of Criminal Justice, 29(5), 429-443.

Tillyer, M. S., Fisher, B. S., \& Wilcox, P. (2011). The effects of school crime prevention on students' violent victimization, risk perception, and fear of crime: A multilevel opportunity perspective. Justice Quarterly, 28(2), 249-278.

doi:10.1080/07418825.2010.493526

Trump, K. (2000). Classroom killers? Hallway hostages? How schools can prevent and manage school crises. Washington, D.C.: Distributed by ERIC Clearinghouse. 
Turner, C., \& Martin, E. (1984). Surveying subjective phenomena. New York: Russell Sage Foundation.

Welsh, W. N. (2001). Effects of student and school factors on five measures of school disorder. Justice Quarterly, 18(4), 911-947.

Zhe, E. J., \& Nickerson, A. B. (2007). Effects of an intruder crisis drill on children's knowledge, anxiety, and perceptions of school safety. School Psychology Review, 36(3), 501-508. 
Table 1: Descriptive Statistics $(\mathrm{N}=352)$

Table 1. Sample Descriptives $(\mathrm{N}=352)$

\begin{tabular}{l|c|c}
\hline Variable & N & Survey \% \\
\hline Individual Characteristics & & \\
\hline Experienced an Active Shooter Drill & 194 & 56.40 \\
Demographics & & 43.32 \\
\hline White & 146 & 49.14 \\
Male & 171 & 50.90 \\
Female & 177 & $\mathrm{M}=22.13(\mathrm{SD}=5.27)$ \\
Age & 343 & $\mathrm{M}=4.13(\mathrm{SD}=5.27)$ \\
Average number of years since high & 343 & \\
school & & \\
\hline School Characteristics & 347 & $\mathrm{M}=4.38(\mathrm{SD}=1.50)$ \\
School Climate (0-8) & \\
Security Awareness $(0-9)^{\mathrm{b}}$ & 333 & $\mathrm{M}=5.94(\mathrm{SD}=1.62)$ \\
High School Size & & 10.66 \\
Small & 37 & 58.21 \\
Medium & 202 & 31.12 \\
$\quad$ Large & 108 & \\
High School Designation & & 90.29 \\
Public & 316 & 9.71 \\
Private & 34 & 5.70 \\
High School Location & & 80.91 \\
Rural & 20 & 13.39 \\
Suburban & 284 & 47 \\
Urban & & \\
\hline
\end{tabular}

Note:

${ }^{a}$ The school climate scale is a summative scale that included information from six questions used to measure a students attachment and bond to their school. All responses were coded as 1 for "Mostly True" and 0 for "Mostly False"

${ }^{\mathrm{b}}$ The security awareness scale is a summative scale that was used to determine how many 
Table 2. Principal Components Analysis of the Dependent Variables

\begin{tabular}{lcc}
\hline & \multicolumn{2}{c}{ Components } \\
\cline { 2 - 3 } Variables & 1 & 2 \\
& Perceived Risk & Student Fear \\
\hline $\begin{array}{l}\text { Did you ever avoid going to school because you felt } \\
\text { threatened on school property }\end{array}$ & .48 & -- \\
$\begin{array}{l}\text { Did you ever stay home from school because you thought } \\
\text { someone might attack or harm you in the school building? }\end{array}$ & .40 & -- \\
$\begin{array}{l}\text { I was worried about an active shooter situation in my high } \\
\text { school }\end{array}$ & .32 & -.55 \\
$\begin{array}{l}\text { Did you ever fear being attacked traveling to or from } \\
\text { school? }\end{array}$ & .42 & .41 \\
Were you ever fearful of being attacked while on the school & .40 & .55 \\
bus? & & .45 \\
\hline How safe did you feel at your high school? (1-10) & -.40 & \\
\hline
\end{tabular}


Table 3: Individual Item Information for School Climate, Security Perceptions, Perceived Risk and Student Fear

\begin{tabular}{|c|c|c|c|c|}
\hline School Climate $(\alpha=.65)$ & Min & Max & $\mathbf{N}$ & Yes/True $(\%)$ \\
\hline I felt like I belonged & 0 & 1 & 351 & 83.48 \\
\hline Groups of students did not get along together & 0 & 1 & 350 & 57.71 \\
\hline The teachers were more like friends than authority figures & 0 & 1 & 350 & 50.29 \\
\hline Students really liked my high school & 0 & 1 & 351 & 19.09 \\
\hline The teachers cared about how students felt & 0 & 1 & 350 & 15.14 \\
\hline The teachers went out of their way to help the students & 0 & 1 & 350 & 18.57 \\
\hline \multicolumn{5}{|l|}{ Security Awareness $(\alpha=.50)$} \\
\hline Security guards or assigned police officers & 0 & 1 & 348 & 86.49 \\
\hline School staff or adults supervising the hallways & 0 & 1 & 347 & 73.49 \\
\hline Metal detectors (including wands) & 0 & 1 & 344 & 23.26 \\
\hline Locked entrance or exit doors during the day & 0 & 1 & 344 & 59.59 \\
\hline Visitor Sign-In Requirements & 0 & 1 & 344 & 87.21 \\
\hline Locker Checks & 0 & 1 & 342 & 42.69 \\
\hline Student badges or picture identification & 0 & 1 & 344 & 40.70 \\
\hline Security Cameras & 0 & 1 & 347 & 88.76 \\
\hline A student code of conduct & 0 & 1 & 346 & 92.49 \\
\hline \multicolumn{5}{|l|}{ Perceived Risk $(\alpha=.70)$} \\
\hline $\begin{array}{l}\text { Did you ever avoid going to school because you felt } \\
\text { threatened on school property }\end{array}$ & 0 & 1 & 349 & 4.01 \\
\hline $\begin{array}{l}\text { Did you ever stay home from school because you thought } \\
\text { someone might attack or harm you in the school building? }\end{array}$ & 0 & 1 & 349 & 4.30 \\
\hline \multicolumn{5}{|l|}{ Student Fear $(\alpha=0.52)$} \\
\hline $\begin{array}{l}\text { I was worried about an active shooter situation in my high } \\
\text { school } \\
\text { Did you ever fear being attacked traveling to or from }\end{array}$ & 0 & 3 & 349 & 18.05 \\
\hline $\begin{array}{l}\text { school? } \\
\text { Were you ever fearful of being attacked while on the }\end{array}$ & 0 & 1 & 349 & 8.31 \\
\hline school bus? & 0 & 1 & 348 & 4.31 \\
\hline
\end{tabular}

Note: $\alpha=$ Alpha coefficient

School climate responses included "Mostly True (1)" and "Mostly False (0)"

Security awareness responses included "Yes (1)" "No/Not Sure (0)"

Four of the responses to student fear questions included "Yes (1)" and "No (0)"; The fifth question that asked whether the student was worried about an active shooter situation was coded as "Strongly Disagree (0)," Disagree (1)," "Agree (2)," and "Strongly Agree (3)" 
Table 4: The Effect of an Active Shooter Drill on Student Fear ( $\mathrm{N}=308)$

\begin{tabular}{lll}
\hline Variable & $\boldsymbol{\beta}$ & SE \\
\hline Experienced an Active Shooter Drill & $0.19^{*}$ & .07 \\
School Climate & $-.05^{*}$ & .02 \\
Security Awareness & $-.05^{*}$ & .02 \\
Small High School & .03 & .13 \\
Large High School & -.01 & .08 \\
Private High School & -.12 & .14 \\
Urban High School & $.32^{* *}$ & .11 \\
White & -.04 & .07 \\
Female & .04 & .07 \\
Age & .00 & .01 \\
Constant & $.57^{*}$ & .26 \\
\hline $\mathbf{R}^{\mathbf{2}}$ & & .08
\end{tabular}

$\beta=$ beta coefficients; $\mathrm{SE}=$ Standard Error

$\mathrm{F}(10,297)$

$* * * p<, 0.001 . * * p<.01 . * p<.05$. 
Table 5: The Effect of an Active Shooter Drill on Perceived Risk (N=309)

\begin{tabular}{lll}
\hline Variable & $\boldsymbol{\beta}$ & SE \\
\hline Experienced an Active Shooter Drill & $.10^{*}$ & .04 \\
School Climate & $-.03^{*}$ & .01 \\
Security Awareness & -.01 & .01 \\
Small High School & -.04 & .07 \\
Large High School & .03 & .04 \\
Private High School & .03 & .08 \\
Urban High School & $.16^{* *}$ & .06 \\
White & .01 & .04 \\
Female & .00 & .04 \\
Age & .00 & .00 \\
Constant & .05 & .15 \\
\hline $\mathbf{R}$ & & .06 \\
\hline
\end{tabular}

$\beta=$ beta coefficients; $\mathrm{SE}=$ Standard Error

$\mathrm{F}(10,298)$

$* * * p<, 0.001 . * * p<.01 . * p<.05$. 
Table 6: Ordinal Logistic Regression Model Predicting Perceptions of School Safety $(\mathrm{N}=308)$

\begin{tabular}{lcc}
\hline Variable & $\boldsymbol{\beta}(\mathbf{S E})$ & OR $(\mathbf{9 5 \%} \mathbf{C I})$ \\
\hline Experienced an Active Shooter Drill in High School & $-.76(.23)^{* * * *}$ & $.47[.30, .73]$ \\
School Climate & $.68(.08)^{* * *}$ & $1.97[1.68,2.30]$ \\
Security Awareness & $.12(.07)$ & $1.13[.98,1.30$ \\
Small High School & $.26(.39)$ & $1.30[.61,2.77]$ \\
Large High School & $.02(.23)$ & $1.02[.64,1.61]$ \\
Private High School & $.07(.43)$ & $.93[.40,2.16]$ \\
Urban High School & $-.32(.32)$ & $.73[.39,1.38]$ \\
White & $.23(.22)$ & $1.26[.82,1.91]$ \\
Female & $-.07(.21)$ & $.93[.62,1.40]$ \\
Age & $.01(.02)$ & $1.01[.96,1.05]$ \\
\hline
\end{tabular}

\begin{tabular}{ll}
\hline Pseudo R & 0.09 \\
\hline Cl & 0.09
\end{tabular}

$\mathrm{CI}=$ confidence interval; $\mathrm{OR}=$ odds ratio; $\beta=$ Beta Coefficient; $\mathrm{SE}=$ Standard Error

LR $\operatorname{chi} 2(11)=93.23$

$* * * p<, 0.001 . * * p<.01 . * p<.05$. 